\title{
Does Relatedness Matter for Online Self-regulated Learning to Promote Perceived Learning Gains and Satisfaction?
}

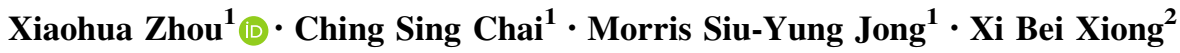

Accepted: 3 April 2021/Published online: 11 May 2021

(C) De La Salle University 2021

\begin{abstract}
The COVID-19 pandemic has moved university teaching and learning activities that conventionally take place in physical classrooms to online platforms. There is an urgent need to investigate university students' experience and perceptions of online learning during the pandemic so as to optimize online learning strategies in tertiary education during and after the pandemic. Based on self-determination theory and the social cognitive perspective, the present study investigated the relationship between perceived relatedness with instructors and classmates, online self-regulated learning (OSRL), perceived learning gains, and satisfaction of 572 Chinese undergraduate students. Through structural equation modeling (SEM) and bootstrapping, we found: (1) relatedness was positively associated with OSRL; (2) relatedness had no direct effect on either perceived learning gains or satisfaction; (3) OSRL has a full mediating effect on the relationship between relatedness and perceived learning gains; (4) there was a serial mediating effect of OSRL and perceived learning gains on the relationship between relatedness and satisfaction; and (5) task strategies and goal setting contributed most to OSRL's mediating effects. Our work provides university instructors, online course designers, and online platform providers with new insights into the importance of supporting undergraduate students' OSRL (particularly task strategies and goal setting) via
\end{abstract}

Xiaohua Zhou

amyzhouxh@link.cuhk.edu.hk

1 Department of Curriculum and Instruction \& Centre for Learning Sciences and Technologies, The Chinese University of Hong Kong, Hong Kong S.A.R., China

2 Faculty of Education, Guangxi Normal University, Guangxi, China developing social connections for improving their perceived learning gains and satisfaction in online learning environments.

Keywords Online self-regulated learning · Relatedness · Perceived learning gains $\cdot$ Satisfaction

\section{Introduction}

The COVID-19 pandemic has pushed many universities to move existing courses online because of social distancing policies. Although online learning is not new in higher education, it is probably the first time that many university students experience intensive online learning for all subjects in social isolation. Whether they are able to experience perceived learning gains from online courses similar to what they perceived with face-to-face courses and how satisfied they are with the online mode need further unpacking. Understanding university students' learning experience and perceptions from multiple perspectives may help inform online course design, pedagogical practice, and platform design during and after COVID-19.

The online mode of instruction demands students assumes more responsibilities for their learning behaviors without teachers' immediate supervision (Barnard et al., 2009; Broadbent \& Poon, 2015). Thus, students' self-regulation becomes vital in predicting learning outcomes (Broadbent \& Poon, 2015; Handoko et al., 2019; Song \& Kim, 2020) and learner satisfaction (Kara et al., 2020).

According to self-determination theory (Deci \& Ryan, 2002), autonomy, competence, and relatedness are basic psychological needs. A social context that satisfies basic psychological needs could foster self-regulation (Deci et al., 1996). One of these basic needs, relatedness, refers to 
the desire to feel connected to others within supportive or close relationships (Reis et al., 2000). In online learning, this was found to be a distinct need from autonomy and competence (Wong, 2020) and is an understudied component (Durksen et al., 2016). In particular, limited research (e.g., Chen \& Chen, 2014) has connected the psychological need of feeling related to others with online self-regulated learning (OSRL). Thus, more research is needed. Social isolation during the pandemic offers a unique context and opportunity to examine the role of relatedness in online learning and OSRL.

\section{Literature Review}

\section{The Social Nature of Online Learning}

Educators generally agree that learning is social in nature (Bransford et al., 1999; Frey et al., 2019). Empirical studies have supported the importance of close social relationships for online learning, in terms of promoting knowledgesharing behavior (Ma \& Yuen, 2011), increasing perceived knowledge gain (Song et al., 2019), and improving learners' satisfaction (Oyarzun et al., 2018). During the pandemic, it is possible that students crave social connection due to the physical isolation from instructors and classmates (Wong, 2020). Correlations were found between relatedness and other learning experience variables (e.g., attention, motivation) in synchronic online learning during COVID-19 (Besser et al., 2020). Nonetheless, the roles of relatedness in the learning process (in terms of self-regulated learning) and learning outcomes (in terms of perceived learning gains and satisfaction) have not been fully investigated and further research is needed to clarify these issues.

\section{Relatedness and OSRL}

From the perspective of self-determination theory (Deci \& Ryan, 2002), autonomy, competence, and relatedness are three basic psychological needs of human beings. Fulfilling these needs could increase self-organization, adjustment, and well-being. Social contexts that satisfy students' basic psychological needs may enable deeper and fuller learning to develop and enhance personal adjustment in the classroom and beyond (Deci et al., 1996, p. 180). Satisfaction of these needs has been found to foster undergraduates' selfdetermined motivation and online learning outcomes (perceived knowledge transfer, perceived learning gains, and grades) (Hsu et al., 2019). Among the three needs, relatedness may be distinct (Durksen et al., 2016). A recent study on online learning among school students during COVID-19 reported that relatedness is not associated with autonomy, while autonomy and competence are correlated (Wong, 2020). Relatedness is centrally important for internalizing regulation (Deci \& Ryan, 2002). Students experiencing relatedness were found more likely to develop identified and integrated regulation for learning tasks than students who felt disconnected from teachers (Niemiec \& Ryan, 2009). Hence, the role of relatedness itself in online learning and particularly in OSRL needs more research.

Moreover, from a social cognitive perspective, human agency occurs within a broad network of social-structural influences (Bandura, 2001). Since self-regulated learning is based on the assumption that individuals can exert their agency for learning, scholars have argued that reciprocal relationships among social, personal, and environmental factors could support the development of self-regulated learning (Barnard-Brak et al., 2010; Schunk, 2001).

Therefore, it seems reasonable to assume that when students take online courses, those who feel closer to their classmates and instructors are more likely to self-regulate their learning. The empirical evidence for the association between relatedness and self-regulated learning was found in face-to-face classrooms (Sidelinger et al., 2015), and in a MOOC (Massive Open Online Courses) setting (Milikic et al., 2020), but apparently it has not been investigated in online courses for formal higher education since the COVID-19 outbreak. The present study attempted to fill this gap, leveraging the current situation.

\section{OSRL, Perceived Learning Gains, and Satisfaction}

It is widely agreed that self-regulation is important for online learning in terms of improving learning performance and student satisfaction (Song \& Kim, 2020; Wang et al., 2013). However, findings on the relative importance of OSRL strategies are not consistent in higher education. A systematic review reported that four out of five studies which investigated time management found it a positive predictor of online academic success in higher education. The mean age of participants in four studies was above 29 (One study did not report age.) (Broadbent \& Poon, 2015). Puzziferro (2008) also found that study environment management significantly predicted final grades and satisfaction with online courses among community college students (mean age $=29$ ). Moreover, goal setting has been found to be a positive predictor and help seeking a negative predictor of personal course goals attainment, while selfevaluation and task strategies predicted only some personal course goals (i.e., completing assessments and lectures) among MOOC learners (mean age $=32.0$, SD $=10.8$ ) (Kizilcec et al., 2017). Furthermore, goal setting was reported to be the only strategy contributing to MOOCs completion, while environmental structuring, task 
strategies, time management, help seeking, and self-evaluation did not make a difference (mean age $=45.75$, SD = 12.23) (Handoko et al., 2019). In short, the effects of OSRL strategies seem to be inconsistently reported and context dependent, warranting further research on OSRL strategies.

The context of online learning during COVID-19 among university students differs from previous studies as regards: (1) Students' background Participants in most of the abovementioned studies were older than the average age (26years) at which people graduate from tertiary level programs (OECD, 2017). This may be due to the online courses in the above-mentioned studies being designed for traditional distance education (e.g., for students who have difficulties in studying full-time or taking courses on campus) or for informal learning (e.g., MOOCs for selfdirected study). Full-time university students who are in their early twenties (or even younger) and older learners who may have job or family duties, and more developed metacognitive abilities (Kizilcec et al., 2017) may use different learning strategies; (2) Instruction mode In the above-mentioned studies, the instruction modes of online courses were not reported in detail, e.g., self-paced or prescheduled; asynchronous, synchronous, or blended delivery, except for one study on self-paced MOOCs (Kizilcec et al., 2017). During the pandemic, many university students need to follow fixed timetables (Zhu, 2020), and synchronous delivery has become popular as evidenced by the explosion in videoconferencing platform usage (Spathis \& Dey, 2020); and (3) Social context Due to social distancing during the pandemic, it is possible that students crave social connection due to physical isolation from instructors and classmates (Wong, 2020). The effects of relatedness may be stronger than in the previous studies before the pandemic. Therefore, it is necessary to examine the OSRL strategies used by full-time university students for formal learning during COVID-19.

Learning gains refer to learning acquired by students at two points in their academic careers (McGrath et al., 2015). Satisfaction reflects students' perception of their learning experience (Kuo et al., 2014). These are well-recognized outcome variables in educational studies and important factors that need further investigation as they comprise an essential part of students' learning experience and could influence their perceptions of the quality of instruction (Elia et al., 2019) and their attitudes towards future online course learning (Dai et al., 2020). Given the unique COVID-19 situation, almost all Chinese university students have experienced fully online learning which offers a unique context to test current theories and practice. Investigating students' perceived learning gains and satisfaction with their online learning experience may help online educators to work on areas that need improvement and to better prepare future online teaching and learning.

\section{The Present Study}

The present study aimed to investigate the relationships between relatedness, OSRL, perceived learning gains, and satisfaction among Chinese undergraduates during the COVID-19 pandemic. The specific research questions include:

(1) What are the relationships between relatedness, OSRL, perceived learning gains, and satisfaction?

(2) What are the roles of OSRL and its specific strategies in the relationships between relatedness, perceived learning gains, and satisfaction?

We proposed the following hypotheses (Fig. 1):

H1: Relatedness predicts OSRL;

$\mathrm{H} 2$ : Relatedness predicts perceived learning gains;

H3: Relatedness predicts satisfaction;

H4: OSRL predicts perceived learning gains;

H5: OSRL predicts satisfaction;

H6: Perceived learning gains predicts satisfaction;

H7: OSRL has a mediating effect on the relationship between relatedness and perceived learning gains;

H8: OSRL and perceived learning gains sequentially mediate the relationship between relatedness and satisfaction;

H9: OSRL has a mediating effect on the relationship between perceived learning gains and satisfaction.

\section{Method}

\section{Participants}

In response to the COVID-19 outbreak, the Ministry of Education in China launched "guidance on the organization and management of online teaching in the higher education institutions during epidemic prevention and control period" in February, 2020. This required national and local governments to encourage universities to implement online education and was promptly adopted by higher education institutions (Ministry of Education, 2020; Zhu \& Liu, 2020). In a public teacher education university in Southwest China which implemented online instruction following the Ministry of Education's guidance, 
Fig. 1 Hypothesized model

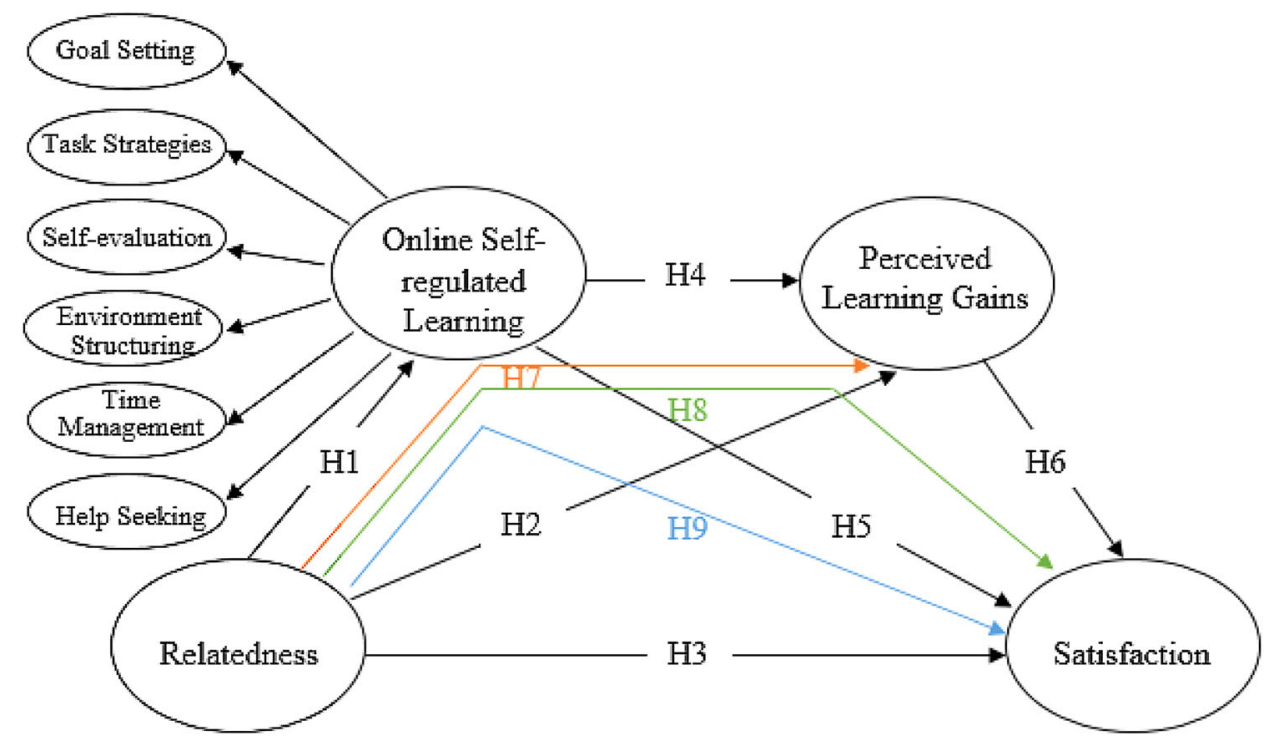

participants were recruited from May to June 2020 through convenience sampling.

A composite online questionnaire was created (see Sect. "Measurements" for details). The students were informed that their participation was voluntary and confidential. A total of 593 undergraduates completed the questionnaire, with an average completion time of around $10 \mathrm{~min}$. Questionnaires that were completed in $120 \mathrm{~s}$ or less were excluded $(n=21)$, following similar practice adopted by previous studies (see Curran, 2016; Xing et al., 2020). It left 572 responses for analyses. The average age of the participants was 19.98 ( $\mathrm{SD}=1.45$ ), and 438 (76.57\%) students were female. The gender distribution was reflective of the student population of the university, a teacher education university, in which the average percentage of female students in the previous 5 years was $72.64 \%$. ${ }^{1}$ The participants were from different years of study (year $1=302(52.80 \%)$, year $2=133(23.25 \%)$, year $3=116(20.28 \%)$, and year $4=21(3.67 \%))$ and different disciplines [social sciences $=232(40.56 \%)$, humanities and arts $=223(38.99 \%)$, natural sciences $=99(17.31 \%)$, and other disciplines $=18(3.15 \%)]$.

\section{Measurements}

OSRL

To measure participants' OSRL, we adapted the Online Self-Regulated Learning Questionnaire (OSLQ, Barnard et al., 2009), which is a 24-item scale measuring six OSRL strategies: goal setting, task strategies, self-evaluation, environment structuring, time management, and help seeking. The original Cronbach's alphas for its six subscales ranged from 0.67 to 0.90 .

As self-regulated learning strategies appear to be "highly context dependent" (Schunk, 2001, p. 125), we substituted four items in OSLQ that did not fit the context of online learning during COVID-19 (e.g., "Although we don't have to attend daily classes, I still try to distribute my studying time evenly across days."2) with corresponding items from the Motivated Strategies for Learning Questionnaire (MSLQ, Pintrich et al., 1993; e.g., "I make sure that I keep up with the weekly readings and assignments for the online lessons."). Moreover, we removed three items that did not fit the context of our study. Thus, the final scale for measuring OSRL consisted of 21 items.

\section{Relatedness}

We measured participants' relatedness to instructors and classmates by four self-developed items.

\section{Perceived Learning Gains}

Since the participants were from different disciplines, their perceived learning gains could not be measured using a single standardized test. Thus, we measured participants' self-perceived improvement with four items based on Sher's (2009) work.

\footnotetext{
${ }^{2}$ Since almost all courses were changed to online mode during COVID-19, many university students in China need to attend to prescheduled classes on a daily basis.
} 


\section{Satisfaction}

We compiled four items from previous studies (Arbaugh, 2000; Artino, 2008; Strachota, 2003) to measure participants' satisfaction levels.

All items were measured using a 5-point Likert scale (from $1=$ strongly disagree to $5=$ strongly agree). All the example items are shown in Table 1. Three experts in curriculum and instruction were consulted for face validity of the items. Ten university students were invited to complete the questionnaire to check readability and completion time.

\section{Data Analysis}

We first calculated descriptive statistics, then checked reliabilities (using Cronbach's alpha and the SpearmanBrown coefficient) of all the scales and validity (by exploratory factor analysis [EFA] and confirmatory factor analysis [CFA]) of the measurement model before conducting the SEM analysis (with bootstrapping), using SPSS 24.0 and Mplus 7.4.

\section{Results}

\section{Reliability and Validity of the Measurements}

The Cronbach's alphas for all scales ranged from 0.67 to 0.93 (Table 2), indicating acceptable internal consistency. An EFA (method: principal components, extraction: varimax) was conducted for items measuring relatedness, perceived learning gains, and satisfaction (12 items altogether), using a split-half sub-sample $(n=286)$. The total variance explained was $79.60 \%$, with factor loadings ranging from 0.64 to 0.86 . Then we conducted CFA on the remaining split-half sub-sample $(n=286)$, which showed a satisfactory model fit: $\chi^{2} / \mathrm{df}=2.55, \mathrm{CFI}=0.97, \mathrm{TLI}=$ 0.96, RMSEA $=0.07$, SRMR $=0.04$; Hair et al., 2010). The factor loadings for each item ranged from 0.67 to 0.95 , except for one item with a factor loading of 0.54 .

As for the scale measuring OSRL, we conducted CFA as it was theoretically based on Barnard et al.'s (2009) conceptions of OSRL. The analysis identified one item in time management ("I attend online lessons regularly.") with low item loading (0.44). After deleting it, the factor loading for each item ranged from 0.58 to 0.87 , with an acceptable model fit $\left(\chi^{2} / \mathrm{df}=3.82, \quad \mathrm{CFI}=0.93, \mathrm{TLI}=0.92\right.$, RMSEA $=0.07$, SRMR $=0.05$; Hair et al., 2010), showing good construct validity.

We also ran CFA for the measurement model including all the measures (32 items in total) for relatedness, OSRL, perceived learning gains, and satisfaction, which showed an acceptable fit: $\chi^{2} / \mathrm{df}=3.59, \mathrm{CFI}=0.91, \mathrm{TLI}=0.90$, RMSEA $=0.07$, SRMR $=0.05$ (Hair et al., 2010), suggesting a valid measurement model for further analyses.

\section{Descriptive Statistics and Correlations}

Table 2 reports the descriptive statistics of and correlations among the key variables. As predicted, relatedness, OSRL's six strategies, perceived learning gains, and satisfaction were closely correlated ( $r$ ranged from 0.46 to 0.76). All correlations were significant at the 0.01 level.

\section{SEM}

To examine the relationships among relatedness, OSRL and its six strategies, perceived learning gains, and satisfaction, we conducted SEM analyses with bootstrapping (number of bootstrap samples $=1000$, bias-corrected

Table 1 Example items in the survey

\begin{tabular}{|c|c|}
\hline Scales & Example item \\
\hline \multicolumn{2}{|l|}{ OSRL } \\
\hline Goal setting & I set standards for my online lesson assignments \\
\hline Task strategies & $\begin{array}{l}\text { I try to take more thorough notes for my online lessons because notes are even more important for learning online than in } \\
\text { a regular classroom }\end{array}$ \\
\hline Self-evaluation & I summarize my learning in the online lessons to examine my understanding of what I have learned \\
\hline $\begin{array}{l}\text { Environment } \\
\text { structuring }\end{array}$ & I choose the location where I have my online lessons to avoid distractions \\
\hline Time management & I make good use of my study time for the online lessons \\
\hline Help-seeking & When I can NOT understand the material in online lessons, I ask other students in the class for help \\
\hline Relatedness & I feel close to my classmates \\
\hline $\begin{array}{l}\text { Perceived learning } \\
\text { gains }\end{array}$ & I have gained a good understanding of the essential concepts in the online lessons \\
\hline Satisfaction & Overall, I am satisfied with the online learning experience \\
\hline
\end{tabular}


Table 2 Descriptive statistics and correlations among key variables

\begin{tabular}{|c|c|c|c|c|c|c|c|c|c|c|c|c|}
\hline & Mean & SD & $\alpha$ & 1 & 2 & 3 & 4 & 5 & 6 & 7 & 8 & 9 \\
\hline 1. Relatedness & 3.68 & 0.66 & 0.84 & - & & & & & & & & \\
\hline 2. Goal setting & 3.63 & 0.66 & 0.90 & 0.51 & & & & & & & & \\
\hline 3. Task strategies & 3.48 & 0.71 & 0.81 & 0.58 & 0.66 & & & & & & & \\
\hline 4. Self-evaluation & 3.70 & 0.65 & 0.79 & 0.71 & 0.65 & 0.70 & & & & & & \\
\hline $\begin{array}{l}\text { 5. Environment } \\
\text { structuring }\end{array}$ & 3.89 & 0.63 & 0.77 & 0.57 & 0.53 & 0.53 & 0.59 & & & & & \\
\hline 6. Time management & 3.69 & 0.66 & $0.72^{\dagger}$ & 0.65 & 0.64 & 0.63 & 0.71 & 0.59 & & & & \\
\hline 7. Help seeking & 3.77 & 0.58 & 0.67 & 0.69 & 0.55 & 0.59 & 0.68 & 0.55 & 0.67 & & & \\
\hline $\begin{array}{l}\text { 8. Perceived learning } \\
\text { gains }\end{array}$ & 3.59 & 0.74 & 0.92 & 0.56 & 0.59 & 0.65 & 0.63 & 0.52 & 0.59 & 0.53 & & \\
\hline 9. Satisfaction & 3.52 & 0.84 & 0.93 & 0.47 & 0.52 & 0.56 & 0.50 & 0.46 & 0.50 & 0.46 & 0.76 & - \\
\hline
\end{tabular}

†Time management has only two items, so the Spearman-Brown coefficient was computed instead of Cronbach's $\alpha$ (Eisinga et al., 2013)

confidence interval $=95 \%$ ). First, we examined a model using OSRL as a higher-order factor of its six strategies (Model 1 in Fig. 2), relatedness was specified as the exogenous variable, while online self-regulated learning, perceived learning gains, and satisfaction were specified as the endogenous variables. Since gender was found to be related to both self-regulated learning (Kuo et al., 2013) and satisfaction (González-Gómez, et al., 2012), and the gender distribution was biased in our sample, gender was treated as a control variable in the SEM analyses by correlating it with all the other variables.

The model fit was acceptable: $\chi^{2} / \mathrm{df}=3.47$; CFI $=0.91$; $\mathrm{TLI}=0.90 ;$ RMSEA $=0.07$; SRMR $=0.05$ (Hair et al., 2010). After controlling gender, we found that: (1) Relatedness was directly associated with OSRL $\left(\beta_{\mathrm{se}}=0.85\right.$, $p<0.001$ ); (2) Relatedness was not associated with perceived learning gains $\left(\beta_{\mathrm{se}}=-0.07, p>0.05\right)$ or satisfaction $\left(\beta_{\mathrm{se}}=0.01, p>0.05\right)$; (3) OSRL was directly associated with perceived learning gains $\left(\beta_{\mathrm{se}}=0.81\right.$, $p<0.001)$ but not satisfaction $\left(\beta_{\mathrm{se}}=0.11, p>0.05\right)$; (4)

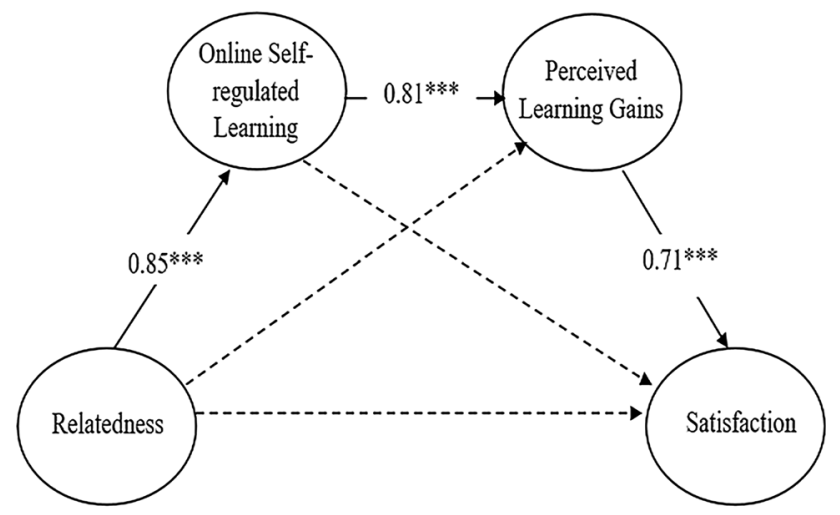

Fig. 2 Model 1. ***p $<0.001$. Solid lines indicate significant paths and dotted lines indicate insignificant paths. Only significant path coefficients are shown
Perceived learning gains were directly associated with satisfaction $\left(\beta_{\mathrm{se}}=0.71, p<0.001\right)$; (5) Relatedness had a significant indirect effect on perceived learning gains through OSRL $\left(\beta_{\mathrm{se}}=0.69, p<0.001\right)$; (6) Relatedness had a significant indirect effect on satisfaction, through OSRL and perceived learning gains in sequence $\left(\beta_{\text {se- }}\right.$ $=0.49, p<0.001)$. The results suggested a full mediating effect of OSRL on the relationship between relatedness and perceived learning gains, and a serial mediating effect of OSRL and perceived learning gains on the relationship between relatedness and satisfaction (Table 3 ).

To ascertain the relative importance of each OSRL strategy and thus provide more specific implications for online course instructors/designers, we further examined the effects of specific OSRL strategies. We replaced the higher-order variable OSRL with each of its six strategies as the mediator one by one, with the other variables remaining the same as in Model 1. The results indicated that only Model 2 and Model 3 showed acceptable fit indices (italics in Table 4). Goal setting played a significant mediating role in the relationship between relatedness and perceived learning gains $\left(\beta_{\mathrm{se}}=0.24, p<0.001\right)$, and the relationship between relatedness, perceived learning gains, and satisfaction $\left(\beta_{\mathrm{se}}=0.17, p<0.001\right)$ (Fig. 3a). Task strategies also played a significant mediating role in the relationship between relatedness and perceived learning gains $\left(\beta_{\mathrm{se}}=0.41, p<0.001\right)$, and the relationship between relatedness, perceived learning gains, and satisfaction $\left(\beta_{\mathrm{se}}=0.29, p<0.001\right)$ (Fig. 3b). The Models 4-7, which did not show acceptable fit indices, are also shown in Fig. 3c-f for reference.

For path coefficients written in the format of $\mathrm{xx} / \mathrm{xx}$ (e.g. "0.39***/0.24***", "-/0.17***"), numbers on the left indicate direct effects while numbers on the right indicate indirect effects (e.g., 0.39: relatedness $->$ perceived learning gains, 0.24: relatedness $->$ goal setting - 
Table 3 Path coefficients in Model 1

\begin{tabular}{|c|c|c|c|c|c|}
\hline \multirow[t]{2}{*}{ Path } & \multirow{2}{*}{$\begin{array}{l}\text { Standardized } \\
\text { estimate }\end{array}$} & \multirow[t]{2}{*}{ S.E } & \multicolumn{2}{|c|}{ Confidence interval } & \multirow[t]{2}{*}{ Hypotheses supported? } \\
\hline & & & Lower & Upper & \\
\hline \multicolumn{6}{|l|}{ Direct effect } \\
\hline $\mathrm{R}->$ OSRL $(\mathrm{H} 1)$ & $0.85 * * *$ & 0.03 & 0.79 & 0.90 & Yes \\
\hline $\mathrm{R}->$ PLG $(\mathrm{H} 2)$ & -0.07 & 0.11 & -0.30 & 0.14 & No \\
\hline $\mathrm{R}->\mathrm{SF}(\mathrm{H} 3)$ & 0.01 & 0.10 & -0.20 & 0.19 & No \\
\hline OSRL $->$ PLG $(\mathrm{H} 4)$ & $0.81 * * *$ & 0.11 & 0.61 & 1.03 & Yes \\
\hline OSRL $->$ SF (H5) & 0.11 & 0.11 & -0.11 & 0.33 & No \\
\hline PLG $->$ SF (H6) & $0.71 * * *$ & 0.06 & 0.60 & 0.83 & Yes \\
\hline \multicolumn{6}{|l|}{ Indirect effect } \\
\hline $\mathrm{R}->$ OSRL $->$ PLG $(\mathrm{H} 7)$ & $0.69 * * *$ & 0.10 & 0.52 & 0.92 & Yes \\
\hline $\mathrm{R}->\mathrm{OSRL}->\mathrm{PLG}->\mathrm{SF}(\mathrm{H} 8)$ & $0.49 * * *$ & 0.08 & 0.37 & 0.70 & Yes \\
\hline $\mathrm{R}->\mathrm{OSRL}->\mathrm{SF}(\mathrm{H} 9)$ & 0.09 & 0.09 & -0.09 & 0.28 & No \\
\hline
\end{tabular}

$R$ relatedness, $O S R L$ online self-regulated learning, $P L G$ perceived learning gains, $S F$ satisfaction

$* * * p<0.001$

Table 4 Model fit indices for Model 2 to Model 7

\begin{tabular}{|c|c|c|c|c|c|}
\hline & $\begin{array}{l}\chi 2 / \mathrm{df} \\
(\leq 5)\end{array}$ & $\begin{array}{l}\text { TLI } \\
(\geq 0.90)\end{array}$ & $\begin{array}{l}\text { CFI } \\
(\geq 0.90)\end{array}$ & $\begin{array}{l}\text { RMSEA } \\
(\leq 0.08)\end{array}$ & $\begin{array}{l}\text { SRMR } \\
(\leq 0.05)\end{array}$ \\
\hline $\begin{array}{l}\text { Model } 2 \\
\text { mediator: goal setting }\end{array}$ & 4.19 & 0.94 & 0.95 & 0.08 & 0.04 \\
\hline $\begin{array}{l}\text { Model } 3 \\
\text { mediator: task strategies }\end{array}$ & 4.41 & 0.93 & 0.94 & 0.08 & 0.04 \\
\hline $\begin{array}{l}\text { Model } 4 \\
\text { mediator: self-evaluation }\end{array}$ & 5.75 & 0.92 & 0.93 & 0.09 & 0.05 \\
\hline $\begin{array}{l}\text { Model } 5 \\
\text { mediator: environment structuring }\end{array}$ & 5.28 & 0.92 & 0.94 & 0.09 & 0.05 \\
\hline $\begin{array}{l}\text { Model } 6 \\
\text { mediator: time management }\end{array}$ & 5.47 & 0.92 & 0.94 & 0.09 & 0.04 \\
\hline $\begin{array}{l}\text { Model } 7 \\
\text { mediator: help seeking }\end{array}$ & 7.02 & 0.89 & 0.91 & 0.10 & 0.06 \\
\hline
\end{tabular}

Models with acceptable model fit indices are shown in italics

$>$ perceived learning gains, 0.17: relatedness $->$ goal setting $->$ perceived learning gains $->$ satisfaction).

\section{Discussion and Conclusions}

\section{Relatedness Promotes OSRL; OSRL Mediates the Effect of Relatedness on Perceived Learning Gains and Satisfaction}

This study supported our hypothesis that meeting the basic psychological need of feeling related to others could contribute to better self-regulation for online learning. Students who perceived relatedness were more likely to self-regulate their learning by using all six OSRL strategies. When students and instructors were separated by space and time, students who feel related to others were more likely to engage in self-regulated learning (e.g., set high standards, prepare themselves before joining in online discussion). This finding aligns with Chiu's (2021) study which reported that relatedness is an important predictor of online learning engagement.

As evidenced in this study, there was no direct effect of relatedness on perceived learning gains and satisfaction. Instead, OSRL fully mediates the relationship between relatedness and perceived learning gains, indicating that 


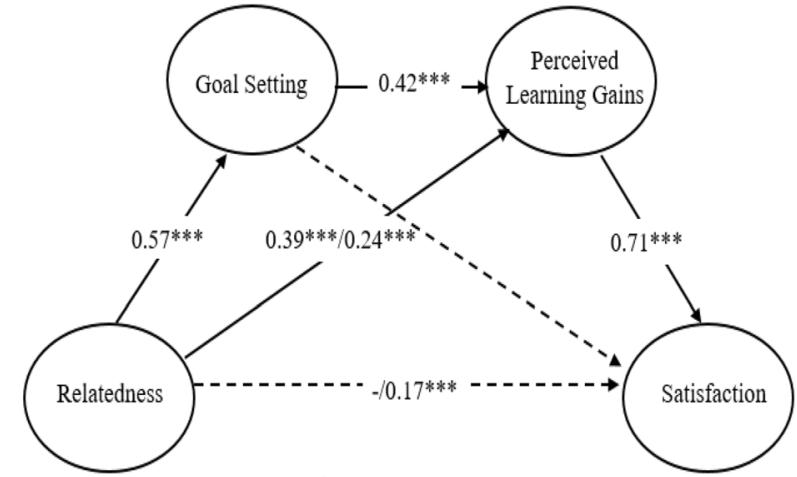

a Model 2

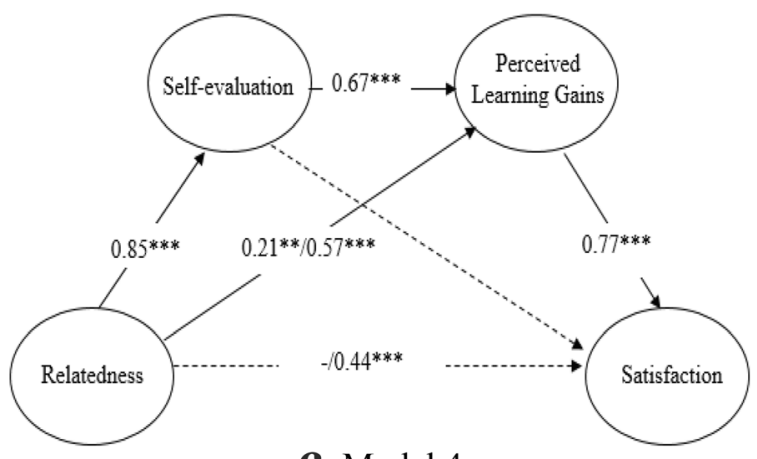

C Model 4

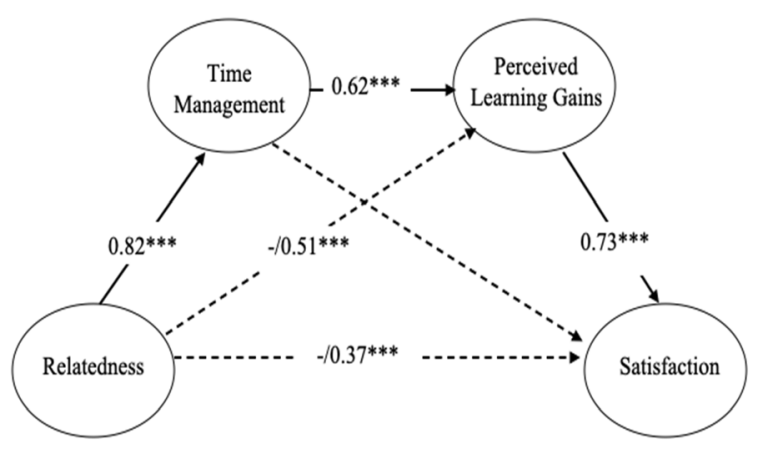

e Model 6
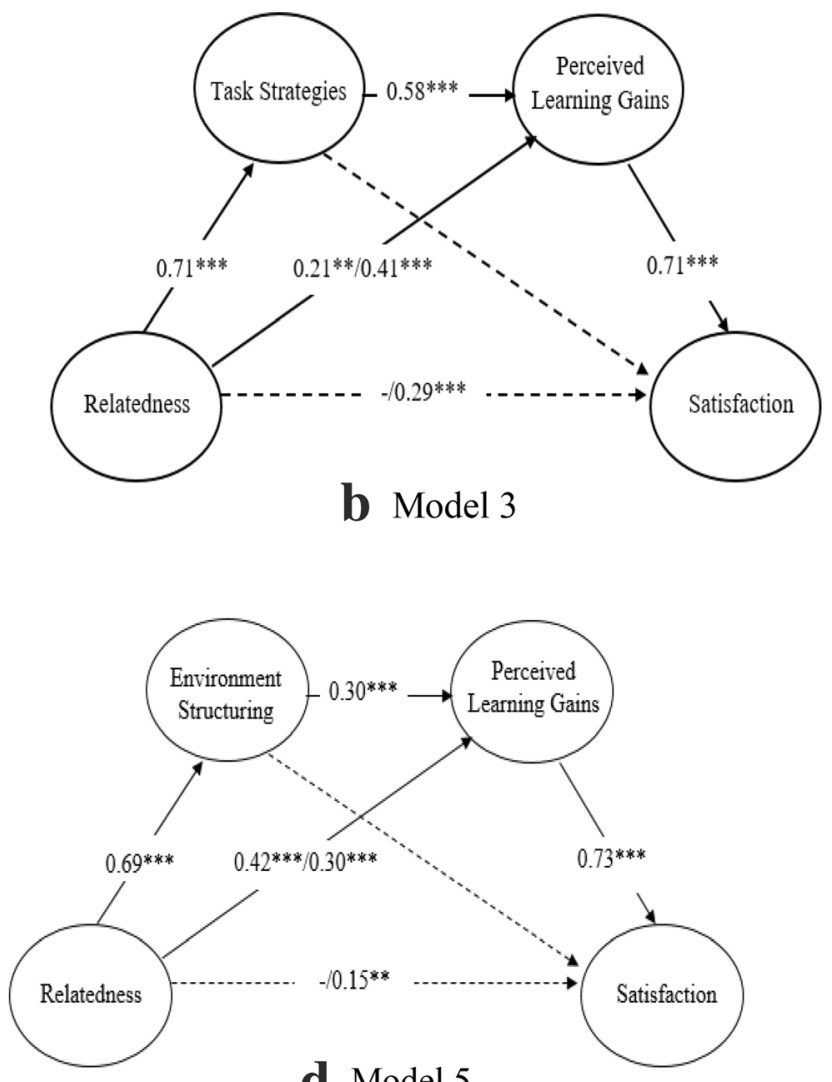

Model 5

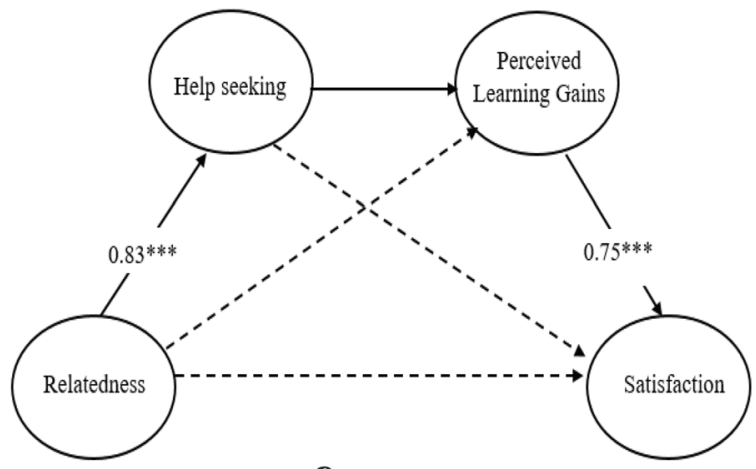

f Model 7

Fig. 3 a Model 2. b Model 3. c Model 4, d Model 5, e Model 6, f Model 7. **p $p<0.01, * * * p<0.001$. Solid lines indicate significant paths and dotted lines indicate insignificant paths. Only significant path coefficients are shown

when university students feel close to their instructors and classmates, they are more likely to regulate their learning, which in turn helps them gain more from online learning. Previous studies reported that a happy teacher-student relationship predicts university students' perceived knowledge gain (Song et al., 2019). This study points to one possible reason for it: relatedness promotes OSRL and OSRL leads to perceived learning gains.

Moreover, OSRL and perceived learning gains play a serial mediating role in the relationship between relatedness and satisfaction. For university students, feeling related to instructors and classmates did not directly lead to satisfaction. The positive effect of relatedness is mediated by OSRL and perceived learning gains in sequence. In other words, feeling close to instructors and classmates makes university students more likely to regulate their learning, which in turn helps them gain more from online learning and thus feel more satisfied with their learning experience. The finding contrasts with Hamdan et al.'s (2021) study during COVID-19 who reported that OSRL directly contributed to satisfaction. This inconsistency might be due to the use of different measurements for 
OSRL (the metacognition self-regulation subscale of MSLQ (Pintrich et al., 1993, 8 items) vs. adapted OSLQ (Barnard et al. 2009, 21 items)), different samples (Jordan university students vs. Chinese university students), and different methods of data analysis (regression vs. SEM). Arguably, the current study seems more rigorous.

These results imply that instructors need to build a learning community and design collaborative learning activities to build relatedness for students to promote their OSRL, in order to improve perceived learning gains and satisfaction. For instance, engaging in group communication, for example students' sharing and constructive peer comments on goal setting and learning strategies, could help them to achieve better grades, which in turn, results in them feeling more satisfied with online learning.

\section{Task Strategies and Goal Setting Contribute Most to Perceived Learning Gains}

Although OSRL's contribution to perceived learning gains was almost unanimous among prior studies, the relative importance of specific OSRL strategies was inconsistently reported (see Sect. "OSRL, Perceived Learning Gains, and Satisfaction"). The present study found that task strategies and goal setting had significant mediating effects on the relationship between relatedness and perceived learning gains.

Task strategies (e.g., taking more thorough notes) would more likely be used when students feel closer to their classmates and instructors. Through completing learning tasks strategically, students achieve more. It is consistent with Broadbent's (2017) finding in a blended learning setting: higher-order learning strategies are important for academic success.

The importance of goal setting found in the present study is congruent with previous findings (Handoko et al., 2019; Kizilcec et al., 2017). This implies that encouraging students to set their goals, supporting students' goal setting with clear course expectations, and reminding students of their goals (e.g., through monthly e-mail reminders) could help them gain more from online learning. Instructors could provide clear course expectations to support students' goal setting.

Previous studies found the role of time management to be a significant factor for older students' learning whose study time may be scare because of job or family duties (e.g., Broadbent, 2017). This does not apply to younger full-time undergraduate students (age $=19.98, \mathrm{SD}=1.45)$. Consequently, instead of focusing on time management, scaffolding goal setting and task strategies may be more effective in helping full-time undergraduates improve perceived learning gains and satisfaction. Merely spending time on learning tasks may not be as helpful as setting goals and completing tasks strategically.

It is noteworthy that although task strategies and goal setting contributed most to perceived learning gains, this does not mean other OSRL strategies were not important. As shown in Model 1, the strategies collectively predicted the perceived learning gains. It is worth putting further research effort into investigating the relationship between different strategies in future.

In conclusion, the answer to whether relatedness matters for OSRL, perceived learning gains, and satisfaction is mixed: relatedness may not directly lead to perceived learning gains and satisfaction, but it may promote OSRL, which in turn, could lead to perceived learning gains and satisfaction. This finding confirmed self-determination theory (Deci \& Ryan, 2002) and social-cognitive theory (Bandura, 2001), and clarified the role of relatedness and self-regulation in the context of online learning during COVID-19. It implies that instructors could develop social ties and build relatedness to promote students' OSRL, help them gain more, and experience satisfaction through online learning.

\section{Limitations and Future Research}

Several limitations of this study should be noted. First, the participants were recruited from a single university in China during the pandemic, which limited the findings' generalizability. Replication of the study with a more representative sample in China and in other cultural contexts after the pandemic is needed to improve the generalizability. Second, the reverse relationship of some online learning strategies (e.g., help seeking) that may promote relatedness was not examined. A longitudinal research design is needed to address the direction of the causality of the relationships. Third, the study measured participants' perceived improvements through a self-reported survey, which may not fully capture their learning gains. Related knowledge or skill-based tests could be adopted in future studies to assess university students' learning gains. Moreover, future research could further examine the underlying mechanism of the relationship between relatedness and OSRL.

Funding Funding of this research work was supported by the National Educational Science Planning Council, China, under grant number XJA190285. 


\section{References}

Arbaugh, J. B. (2000). Virtual classroom characteristics and student satisfaction with internet-based MBA courses. Journal of Management Education, 24(1), 32-54.

Artino, A. R. (2008). Motivational beliefs and perceptions of instructional quality: Predicting satisfaction with online training. Journal of Computer Assisted learning, 24(3), 260-270.

Bandura, A. (2001). Social cognitive theory: An agentic perspective. Annual Review of Psychology, 52(1), 1-26.

Barnard, L., Lan, W. Y., To, Y. M., Paton, V. O., \& Lai, S. L. (2009). Measuring self-regulation in online and blended learning environments. The Internet and Higher Education, 12(1), 1-6.

Barnard-Brak, L., Paton, V. O., \& Lan, W. Y. (2010). Profiles in selfregulated learning in the online learning environment. International Review of Research in Open and Distributed Learning, 11(1), 61-80.

Besser, A., Flett, G. L., \& Zeigler-Hill, V. (2020). Adaptability to a sudden transition to online learning during the COVID-19 pandemic: Understanding the challenges for students. Scholarship of Teaching and Learning in Psychology. https://doi.org/ $10.1037 / \mathrm{st} 10000198$.

Bransford, D., Brown, A., \& Cocking, R. (Eds.). (1999). How people learn: Brain, mind, experience and school. . National Academies Press.

Broadbent, J. (2017). Comparing online and blended learner's selfregulated learning strategies and academic performance. The Internet and Higher Education, 33, 24-32.

Broadbent, J., \& Poon, W. L. (2015). Self-regulated learning strategies \& academic achievement in online higher education learning environments: A systematic review. The Internet and Higher Education, 27, 1-13. https://doi.org/10.1016/j.iheduc. 2015.04.007.

Chen, P. J., \& Chen, Y. H. (2014). Facilitating MOOCs learning through weekly meet-up: A case study in Taiwan. In Proceedings of the first ACM conference on learning @ Scale Conference, pp. 183-184.

Chiu, T. K. F. (2021). Applying the self-determination theory (SDT) to explain student engagement in online learning during the pandemic. Journal of Research on Technology in Education. 117. https://doi.org/10.1080/15391523.2021.1891998.

Curran, P. G. (2016). Methods for the detection of carelessly invalid responses in survey data. Journal of Experimental Social Psychology, 66, 4-19.

Dai, H. M., Teo, T., Rappa, N. A., \& Huang, F. (2020). Explaining Chinese university students' continuance learning intention in the MOOC setting: A modified expectation confirmation model perspective. Computers \& Education, 150, 103850.

Deci, E. L., Ryan, R. M., \& Williams, G. C. (1996). Need satisfaction and the self-regulation of learning. Learning and Individual Differences, 8(3), 165-183.

Deci, E. L., \& Ryan, R. M. (2002). Self-determination research: Reflections and future directions. In E. L. Deci \& R. M. Ryan (Eds.), Handbook of Self-determination research. (pp. 431-441). University of Rochester Press.

Durksen, T. L., Chu, M. W., Ahmad, Z. F., Radil, A. I., \& Daniels, L. M. (2016). Motivation in a MOOC: A probabilistic analysis of online learners' basic psychological needs. Social Psychology of Education, 19(2), 241-260.

Eisinga, R., Te Grotenhuis, M., \& Pelzer, B. (2013). The reliability of a two-item scale: Pearson, Cronbach, or Spearman-Brown? International Journal of Public Health, 58(4), 637-642.

Elia, G., Solazzo, G., Lorenzo, G., \& Passiante, G. (2019). Assessing learners' satisfaction in collaborative online courses through a big data approach. Computers in Human Behavior, 92, 589-599.
Frey, N., Fisher, D., \& Smith, D. (2019). All learning is social and emotional: Helping students develop essential skills for the classroom and beyond. . ASCD.

González-Gómez, F., Guardiola, J., Rodríguez, Ó. M., \& Alonso, M. Á. M. (2012). Gender differences in e-learning satisfaction. Computers \& Education, 58(1), 283-290.

Hair, J. F., Jr., Black, W. C., Babin, B. J., Anderson, R. E., \& Tatham, R. L. (2010). SEM: An introduction. Multivariate data analysis: A global perspective. (7th ed., pp. 629-686). Pearson Education.

Hamdan, K. M., Al-Bashaireh, A. M., Zahran, Z., Al-Daghestani, A., Samira, A. H., \& Shaheen, A. M. (2021). University students' interaction, internet self-efficacy, self-regulation and satisfaction with online education during pandemic crises of COVID-19 (SARS-CoV-2). International Journal of Educational Management. https://doi.org/10.1108/IJEM-11-2020-0513.

Handoko, E., Gronseth, S., McNeil, S., Bonk, C., \& Robin, B. (2019). Goal setting and MOOC completion: A study on the role of selfregulated learning in student performance in massive open online courses. International Review of Research in Open and Distributed Learning. https://doi.org/10.19173/irrodl.v20i4.4270

Hsu, H. C. K., Wang, C. V., \& Levesque-Bristol, C. (2019). Reexamining the impact of self-determination theory on learning outcomes in the online learning environment. Education and Information Technologies, 24(3), 2159-2174.

Kara, M., Kukul, V., \& Çakir, R. (2020). Self-regulation in three types of online interaction: How does it predict online preservice teachers' perceived learning and satisfaction? The Asia-Pacific Education Researcher. https://doi.org/10.1007/ s40299-020-00509-X.

Kizilcec, R. F., Pérez-Sanagustín, M., \& Maldonado, J. J. (2017). Self-regulated learning strategies predict learner behavior and goal attainment in massive open online courses. Computers \& Education, 104, 18-33.

Kuo, Y. C., Walker, A. E., Belland, B. R., \& Schroder, K. E. (2013). A predictive study of student satisfaction in online education programs. International Review of Research in Open and Distributed Learning, 14(1), 16-39.

Kuo, Y. C., Walker, A. E., Schroder, K. E., \& Belland, B. R. (2014). Interaction, internet self-efficacy, and self-regulated learning as predictors of student satisfaction in online education courses. The Internet and Higher Education, 20, 35-50.

Ma, W. K., \& Yuen, A. K. (2011). Understanding online knowledge sharing: An interpersonal relationship perspective. Computers and Education, 56(1), 210-219.

McGrath, C. H., Guerin, B., Harte, E., Frearson, M., \& Manville, C. (2015). Learning gain in higher education. . RAND Corporation.

Milikic, N., Gasevic, D., \& Jovanovic, J. (2020). Measuring effects of technology-enabled mirroring scaffolds on self-regulated learning. IEEE Transactions on Learning Technologies, 13(1), $150-163$.

Ministry of Education of P.R. China. (2020). Guidance on the organization and management of online teaching in the higher education institutions during epidemic prevention and control period. Retrieved March 12, 2021, from http://www.moe.gov.cn/ jyb_xwfb/gzdt_gzdt/s5987/202002/t20200205_418131.html.

Niemiec, C. P., \& Ryan, R. M. (2009). Autonomy, competence, and relatedness in the classroom: Applying self-determination theory to educational practice. Theory and Research in Education, 7(2), 133-144.

OECD. (2017). Education at glance: OECD indicators. Retrieved March 12, 2021, from https://www.oecd-ilibrary.org/docserver/ eag-2017-9-en.pdf?expires $=1607838950 \& i d=i d \&$ accname $=$ ocid177302\&checksum=193EA4306FB3016484A3435733CA C4D9\#: :text=Across $\%$ 20OECD\%20countries\%20with\%20data,from 
$\% 20 \mathrm{a} \% 20$ tertiary $\% 20$

level\%20programme.\&text=Graduation $\% 20$ rates $\% 20$

are $\% 20$ the $\% 20$ estimated,to $\% 20$ graduate $\% 20$ in $\%$

20their\%20lifetime.

Oyarzun, B., Stefaniak, J., Bol, L., \& Morrison, G. R. (2018). Effects of learner-to-learner interactions on social presence, achievement and satisfaction. Journal of Computing in Higher Education, 30(1), 154-175.

Pintrich, P. R., Smith, D. A., Garcia, T., \& McKeachie, W. J. (1993). Reliability and predictive validity of the motivated strategies for learning questionnaire (MSLQ). Educational and Psychological Measurement, 53(3), 801-813.

Puzziferro, M. (2008). Online technologies self-efficacy and selfregulated learning as predictors of final grade and satisfaction in college-level online courses. The American Journal of Distance Education, 22(2), 72-89.

Reis, H. T., Sheldon, K. M., Gable, S. L., Roscoe, J., \& Ryan, R. M. (2000). Daily well-being: The role of autonomy, competence and relatedness. Personality and Social Psychology Bulletin, 26, 419435. https://doi.org/10.1177/0146167200266002.

Schunk, D. H. (2001). Social cognitive theory and self-regulated learning. In B. J. Zimmerman \& D. H. Schunk (Eds.), Selfregulated learning and academic achievement: Theoretical perspectives. (2nd ed.). Lawrence Erlbaum Associates.

Sher, A. (2009). Assessing the relationship of student-instructor and student-student interaction to student learning and satisfaction in web-based online learning environment. Journal of Interactive Online Learning, 8(2), 102-120.

Sidelinger, R. J., Bolen, D. M., McMullen, A. L., \& Nyeste, M. C. (2015). Academic and social integration in the basic communication course: Predictors of students' out-of-class communication and academic learning. Communication Studies, 66(1), 63-84.

Song, D., \& Kim, D. (2020). Effects of self-regulation scaffolding on online participation and learning outcomes. Journal of Research on Technology in Education. https://doi.org/10.1080/1539 1523.2020.1767525.

Song, H., Kim, J., \& Park, N. (2019). I know my professor: Teacher self-disclosure in online education and a mediating role of social presence. International Journal of Human-Computer Interaction, 35(6), 448-455.

Spathis, P., \& Dey, R. (2020, August 5-6). What is zoom not telling you: Lessons from an online course during COVID-19. ACM Sigcomm Education Workshop 2020. http:/gaia.cs.umass. edu/sigcomm_education_workshop_2020/papers/ sigcommedu20-final16.pdf.

Strachota, E. M. (2003). Student satisfaction in online courses: An analysis of the impact of learner-content, learner-instructor, learner-learner and learner-technology interaction (order no. 3100902). Available from ProQuest Dissertations \& Theses A\&I. (305284514). Retrieved August 18, 2020 from http://easyaccess.lib.cuhk.edu.hk/login?url=https:// search.proquest.com/docview/305284514 ? accountid=10371.

Wang, C. H., Shannon, D. M., \& Ross, M. E. (2013). Students' characteristics, self-regulated learning, technology self-efficacy, and course outcomes in online learning. Distance Education, $34(3), 302-323$.

Wong, R. (2020). When no one can go to school: Does online learning meet students' basic learning needs?. Interactive Learning Environments. https://doi.org/10.1080/10494820.2020.1789672.

Xing, W., Ao, L., Xiao, H., \& Liang, L. (2020). Chinese nurses' preferences for and attitudes about e-learning in continuing education: a correlational study. The Journal of Continuing Education in Nursing, 51(2), 87-96.

Zhu, T. (2020). Empirical research on the application of online teaching in Chinese colleges and universities under the situation of novel coronavirus pneumonia prevention and control. International Journal of Emerging Technologies in Learning (iJET), 15(11), 119-136.

Zhu, X., \& Liu, J. (2020). Education in and after Covid-19: Immediate responses and long-term visions. Postdigital Science and Education, 2(3), 695-699.

Publisher's Note Springer Nature remains neutral with regard to jurisdictional claims in published maps and institutional affiliations. 